\title{
Induction of flight via midbrain projections to the cuneiform nucleus
}

\author{
Emmy Tsang ${ }^{1 *}$, Camilla Orlandini ${ }^{1,2 *}$, Rahul Sureka, Alvaro H. Crevenna ${ }^{1}$, Emerald Perlas ${ }^{1}$, \\ Izzie Prankerd ${ }^{1,3}$, Maria E. Masferrer ${ }^{1}$, and Cornelius T. Gross ${ }^{1} \dagger$
}

${ }^{1}$ Epigenetics \& Neurobiology Unit, EMBL Rome, European Molecular Biology Laboratory, Via Ramarini 32, 00015 Monterotondo (RM), Italy

${ }^{2}$ Neurobiology Master's Program, Sapienza University, Piazzale Aldo Moro, Rome, Italy

${ }^{3}$ University of Bath, Bath, UK

* equal contribution

$\dagger$ to whom correspondence should be addressed: gross@embl.it,

\begin{abstract}
The dorsal periaqueductal gray is a midbrain structure implicated in the control of defensive behaviors and the processing of painful stimuli. Electrical stimulation or optogenetic activation of excitatory neurons in dorsal periaqueductal gray results in freezing or flight behavior at low or high intensity, respectively. However, the output structures that mediate these defensive behaviors remain unconfirmed. Here we carried out a targeted classification of neuron types in dorsal periaqueductal gray using multiplex in situ sequencing and then applied cell-type and projection-specific optogenetic stimulation to identify projections from dorsal periaqueductal grey to the cuneiform nucleus that promoted goal-directed flight behavior. These data confirmed that descending outputs from dorsal periaqueductal gray serve as a trigger for directed escape behavior.
\end{abstract}




\section{Introduction}

The periaqueductal gray $(\mathrm{PAG})$ is a brainstem structure that plays a core role in the production of defensive behavior and related autonomic output as well as the processing of painful stimuli (Machado et al., 2003; Mobbs et al., 2003; LeDoux et al., 2012; Silva et al., 2013; Tovote et al., 2016; Franklin et al., 2017; Silva \& McNaughton, 2019). PAG is divided into functional domains - called columns (Bandler and Shipley, 1994) - based on histochemical stains, afferent and efferent connectivity, and electrical and chemical stimulation studies in laboratory rodents. Dorsal PAG (dPAG) consists of the dorsomedial, dorsolateral, and lateral PAG and receives the vast majority of its inputs from the thalamus and hypothalamus (Simerly \& Swanson, 1988; Canteras, Simerly \& Swanson, 1992; Canteras \& Swanson, 1992; Risold, Canteras \& Swanson, 1994; Canteras, Simerly \& Swanson, 1994; Thompson \& Swanson, 1998; Franklin et al., 2017) and provides outputs to medulla and spinal cord. Electrical stimulation of dPAG evokes freezing and flight behavior as well as sympathetic arousal in rodents, cats, and primates (Fanselow, 1991; Behbehani, 1995; Vargas, Marques \& Schenberg, 2000; Bittencourt et al., 2004) and intense sensations of fear and being chased in humans (Nashold, Wilson \& Slaughter, 1969; Amano et al., 1978). Cytotoxic lesions or pharmacogenetic inhibition of dPAG, on the other hand, reduce defensive responses to predator or conspecific threats (Silva et al., 2013; Evans et al., 2018; de Andrade et al., 2019) demonstrating that dPAG is a major conduit for the production of innate defensive responses to threat across mammals (Gross \& Canteras, 2012).

Recent single unit recording studies have identified at least two neural populations in dPAG that are active during approach-avoidance behavior (Deng, Xiao \& Wang, 2016; Masferrer et al., 2020; Rossier et al., 2021). One of these, called Assessment cells, showed a gradual increase in firing activity as the animal approached a threat, while the other, called Flight cells, did not respond appreciably during approach. When the animal reached the closest point of approach to the threat - just before the animal turned to flee - Assessment and Flight cells showed a dramatic switch in firing activity. Assessment cells abruptly shut off their activity while Flight cells abruptly increased their firing. As the animal completed its flight, Flight cell activity dropped back to baseline. Flight cells have also been recorded during visually elicited flight to a looming stimulus where approach does not occur (Evans et al. 2018). This dual encoding of sensory and motor behavior in separate neuron classes in 
dPAG is consistent with a sensory-motor transformation and its role as a trigger for defensive flight.

How does activity in dPAG trigger high speed escape behavior? Anatomical tract tracing suggested that dPAG neurons project to several downstream brainstem structures known to produce locomotor behavior, including the mesencephalic locomotor region (MLR) and lateral paragigantocellularis nucleus (LPGi; Meller and Dennis, 1991). Recent cell-type specific optogenetic activation showed that a prominent target of dPAG in MLR, the cuneiform nucleus $(\mathrm{CnF})$, is capable of producing high speed locomotor responses, raising the possibility that $\mathrm{dPAG}$ projections to $\mathrm{CnF}$ may provide a key output for defensive escape (Redgrave et al., 1988; Caggiano et al., 2018; Sandner et al., 1992; Dielenberg, Hunt, \& McGregor, 2001). Here we use multiplex spatial gene expression analysis to identify a core set of neuronal cell types in $\mathrm{dPAG}$, functionally test whether they are able to mediate defensive escape, examine their anatomical projections to $\mathrm{CnF}$, and determine whether these projections are able to drive goal-directed flight behavior in laboratory mice. Our findings argue that excitatory $\mathrm{dPAG}$ projections to $\mathrm{CnF}$ are likely to be a major $\mathrm{dPAG}$ output for high-speed defensive escape.

\section{Results}

\section{Single-cell multiplex gene expression profiling identifies dorsal PAG cell-types}

Initially, we carried out single cell multiplex gene expression profiling to classify neuron types in the dorsal periaqueductal gray (dPAG) of the mouse brainstem for subsequent functional characterization. Multiplex in situ sequencing (ISS; Lein, Borm \& Linnarsson, 2017; Asp et al., 2020; Lee, 2020) was used to localize a set of known marker genes (Vglut2, Vgat, Gad2, Nos1, Map2, Grin2b, and Tac2) in fresh frozen brain sections of PAG taken just rostral to the oculomotor nucleus. The spatial distribution of transcripts matched well to those reported previously for the individual genes with enrichment of Gad2 and Vgat in vlPAG, Nos 1 in dlPAG, and Tac2 in dmPAG (Allen Brain Atlas; Fig. 1A). Co-localization to putative cell bodies in APAG using a DAPI-derived selective spatial mask and stringent quality control signal thresholding revealed clearly segregating populations of excitatory and inhibitory neurons (Vglut $2+/ G a d 2+/ V g a t+$ vs. Vglut $2+$, 
25/357; Vglut2+/Gad2+/Vgat+ vs. Vgat+/Gad2+, overlap=20/158; Fig. 1B). The relatively stringent quality control for gene transcript detection using ISS suggest that false positives are limited and we interpret the overlap of glutamatergic and GABAergic markers to reflect noise in the co-localization estimation derived from the misassignment of transcripts located in nearby cell processes to local cell bodies, although the presence of neurons that co-release glutamate and GABA has not been sufficiently systematically examined to be categorically ruled out. Co-localization of excitatory and inhibitory markers with Nos 1 and Tac2, two genes that mark columns within the dPAG, revealed that $70 \%$ of Nos $1+$ cells were excitatory (30/43 cells), while $43 \%$ and $55 \%$ of Tac $2+$ cells were excitatory and inhibitory, respectively (Fig 1C). These data demonstrate that there are diverse subsets of spatially segregated excitatory neurons in dPAG and suggest that one or more of them may be responsible for the reported ability of optogenetic stimulation of excitatory neurons in dPAG to elicit flight.

Figure 1 about here

Figure 1. Colocalization of Nos1 and Tac2 with excitatory and inhibitory cells in PAG (A) Localization of Vglut2, Vgat, Gad2, Nos1, and Tac2 transcripts in PAG using multiplex in situ sequencing (ISS) showed regional patterns consistent with prior single gene in situ hybridization methods. DAPI signal was used to identify isolated cells and assign amplified ISS signals to putative single cells. The location of isolated cells that satisfied quality control criteria are represented by a single dot. (B) Representative images of cells classified as glutamatergic (red arrow), GABAergic (green arrow), Tac2+ (pink arrow), Nos 1+ (purple arrow), or unclassified (white arrow). Genes were considered present if they showed at least two high quality (score $>2$ ) spots ( Vgat and Gad2 were considered equivalent) that fell within an expanded perimeter of DAPI signal (dotted line). (C) Distribution of co-expression of glutamatergic and GABAergic markers and their co-localization with Nos 1 and Tac2 in dPAG.

\section{Optogenetic activation of excitatory neurons elicits goal-direct flight}

Next, we performed optogenetic activation of selected neuron types in dPAG in order to determine whether they were capable of promoting flight behavior. Previous studies had reported that ChR2 activation of Vglut2+, but not Gad2+ neurons in APAG elicited a combination of freezing and flight, with the later behavior dominating at higher stimulation 
intensity (Tovote et al., 2016; Deng et al., 2016; Evans et al., 2018). To confirm and extend these findings mice carrying either Vglut2::Cre, Gad2::Cre, Tac2::Cre, Adcyap::Cre, or Nos $1::$ Cre were bilaterally injected with adeno-associated-virus expressing Cre-dependent ChR2 (AAV-hSyn::DIO-ChR2-YFP) or control virus (AAV-hSyn::YFP) into dPAG followed by the surgical placement of optical fibers over the injection areas (Fig. 2A; Fig. S1A,C). Light stimulation of mice was performed in a novel chamber containing a cardboard shelter following 5 minutes of habituation. Light stimulation of ChR2-expressing animals carrying the Vglut2::Cre and Adcyap::Cre transgenes showed clear freezing and flight responses when compared to YFP-expressing control animals, while those of mice carrying Gad2::Cre, Tac2::Cre, Nos $1:$ Cre transgenes did not show any detectable behavioral response. Flight responses in Vglut2::Cre mice were dose-dependent, as they showed greater intensity with increased light power or frequency (Fig. 2BC). Latency to initiate flight typically occured within one second following stimulation onset, but, unlike flight intensity, was not significantly affected by light frequency (Fig. 2DE). Notably, light-evoked flight in Vglut2::Cre infected mice resulted in a rapid retreat into the shelter, with mice turning and running toward the shelter where they then remained for an extended period (Fig. 2E). Light stimulation of ChR2-expressing mice led to a significantly shorter latency to return to the shelter when compared to YFP-expressing control animals (Fig. 2F).

To determine whether stimulation of dPAG neurons that elicit flight was aversive mice carrying the Vglut2::Cre transgene were infected bilaterally with ChR2 or YFP control expressing viruses and surgically implanted with optic fibers above the infection site as above and allowed to habituate to a dual chamber real-time place preference (RTPP) apparatus. Following habituation, light was delivered $(20 \mathrm{~Hz}, 10 \mathrm{~mW})$ to the brain while the animal was in the preferred side of the apparatus. In nearly all animals expressing ChR2 light stimulation elicited escape to the opposite chamber and a failure to return to the stimulus chamber that resulted in a significant reduction of total time spent in the stimulus chamber when compared to YFP-expressing control animals (Fig. 2GH). These data indicate that optogenetic activation of excitatory neurons in $\mathrm{dPAG}$ is aversive. 
Figure 2. Optogenetic stimulation of dPAG excitatory neurons elicits escape. (A) Graphical representation of experimental strategy for optogenetic activation of excitatory cells in dPAG and representative histology of virus expression and fibre placement (solid line; SC, superior colliculus; dPAG, dorsal periaqueductal grey; Aq, aqueduct; scale bar, $250 \mu \mathrm{m}$ ). (B) Probability of observing flight upon optical stimulation of Vglut $2+$ neurons in dPAG with increasing frequency and intensity (ChR2-expressing mice, $\mathrm{N}=$ 9, 5 trials per animal). (C) Evoked velocity aligned to flight onset $(\mathrm{t}=0)$ upon optical stimulation at $10 \mathrm{~mW}$ at three different frequencies ( $\mathrm{N}=$ number of trials). (D) Latency to elicit flight following optical stimulation $(10 \mathrm{~mW})$. Comparison between low and high frequency showed no significant difference (each blue dot represents a single subject). (E) Representative example of escape to shelter upon light stimulation in a ChR2-expressing animal $(\mathrm{t}=0$ indicates beginning of stimulation). (F) ChR2-expressing animals showed a short latency to escape to the shelter upon optical stimulation compared to the control group (ChR2 animals: $\mathrm{N}=11$, YFP animals: $\mathrm{N}=6$; Mann-Whitney unpaired t test, $\mathrm{P}=0.0002$ ). (G) ChR2-expressing animals avoided significantly more the stimulation chamber during the stimulation epoch when compared to YFP-expressing controls (ChR2: $\mathrm{N}=11$, YFP: $\mathrm{N}=8$; multiple $\mathrm{t}$-test with Holm Sidak post hoc, $\mathrm{t}=6.44$, adjusted $\mathrm{P}<0.0001)$. (H) Path of a representative ChR2-expressing animal during the habituation (left) and stimulation (right) epoch in the real-time place preference test; stimulation chamber is on the left.

\section{Projections to the cuneiform nucleus elicit goal-directed flight}

The dorsal PAG projects to a set of downstream brainstem structures implicated in locomotion control, including lateral paragigantocellularis nucleus (LPGi), cuneiform nucleus (CnF), superior colliculus (SC), lateral parabrachial nucleus (LPBS) and pedunculopontine nucleus (PPN; Redgrave et al., 1988, Meller \& Dennis, 1991, Caggiano et al., 2018). In particular, stimulation of $\mathrm{CnF}$ has been shown to evoke high-speed running (Sandner et al., 1992; Dielenberg, Hunt,\& McGregor, 2001; Caggiano et al., 2018) while LPGi was found to harbor excitatory and inhibitory neuron populations that promote and inhibit locomotion, respectively (Capelli et al., 2017). To test whether dPAG excitatory neurons project to $\mathrm{CnF}$ we delivered the presynaptic fluorescent fusion protein Synaptophysin-iRFP to Vglut2+ neurons in dPAG. An examination of iRFP signal in these animals revealed prominent presynaptic boutons in both $\mathrm{CnF}$ and the immediately ventral LPBS, but not in the core LPB or surrounding inferior colliculus (IC; Fig. 3A). To determine whether projections from $\mathrm{dPAG}$ to $\mathrm{CnF}$ derived from a particular column or cell-type, we combined deposition of the retrograde fluorescent tracer cholera toxin B 
(CTB) in $\mathrm{CnF}$ and AAV-mediated fluorescent tagging of excitatory and inhibitory neurons in dPAG (Fig. 3B). Fluorescent retrograde signal was restricted to the dorsolateral PAG consistent with earlier data using non-fluorescent anterograde tracers (Rizvi et al., 1992; Wiberg, 1992; Fig. 3C). Colocalization of retrograde fluorescent signal with cell-type restricted expression of the mCherry fluorophore revealed the majority of projection neurons to be excitatory (Vglut2+: $74.9 \%, \mathrm{~N}=3$ ) and a minority inhibitory (Gad2+: $21.1 \%, \mathrm{~N}=3$ ). These data demonstrate that both excitatory and inhibitory neurons in the dorsolateral PAG project to $\mathrm{CnF}$ (Fig. 3D).

Figure 3 about here

Figure 3. Projections from dIPAG to the cuneiform nucleus. (A) Vglut2+ cells in dPAG project to the cuneiform nucleus $(\mathrm{CnF})$ and to the superior lateral parabrachial nucleus (LPBS). Cre-dependent Synaptophysin-iRFP expressing virus was injected in $\mathrm{dPAG}$ of a $\mathrm{Vglut} 2::$ Cre transgenic animal. Sections show synaptic boutons expressing Synaptophysin-iRFP in CnF and LPBS (IC, Inferior Colliculus; Blue, DAPI). (B) Graphical representation of experimental strategy for retrograde labeling with CTB and identification of glutamatergic (Vglut2+) or GABAergic (Gad2+) identity of projection neurons. (C) Cell bodies of $\mathrm{CnF}$ afferents in PAG were limited to the dorsolateral column (green, $\mathrm{CTB}$; left, $\mathrm{CnF}$; right, PAG; blue, DAPI; scale bar, $250 \mu \mathrm{m}$ ). (D) CTB label (green) in PAG co-localized with both (left) glutamatergic (red) and (right) GABAergic (red) neurons (scale bar, $50 \mu \mathrm{m}$ ).

Finally, we examined whether the projection from PAG to $\mathrm{CnF}$ could elicit goal-directed flight behavior. Cre-dependent ChR2 or YFP-expressing viruses were unilaterally delivered to dPAG, while a retrograde transported Cre-expressing virus was co-delivered unilaterally into $\mathrm{CnF}$ together with an iRFP-expressing virus to delineate the infection zone (Fig. 4A). Because AAV-mediated infection of axons is less narrowly localized to the injection site than CTB retrograde labeling in dPAG was more widespread (Fig. 3C vs. Fig. 4B). Optogenetic activation of retrograde ChR2-expressing neurons in dPAG elicited flight behavior in a dose-dependent manner (Fig. 4C) and with latencies of less than one second (Fig. 4D). Notably, flight responses elicited by light stimulation of ChR2-expressing dPAG projection neurons were directed toward the shelter (Fig. 4E) and 
showed a significantly lower latency to escape than YFP-expressing control animals (Fig. 4F).

Figure 4 about here

Figure 4. Optogenetic stimulation of dPAG neurons that project to $\mathrm{CnF}$ elicits goal-directed flight. (A) Graphical representation of experimental strategy for optogenetic activation of dPAG neurons that project to CnF. (B) Representative histology of Cre-dependent ChR2 expression (green) and fibre placement (solid line) in (left) dPAG and (right) site of retrograde viral injection in $\mathrm{CnF}$ (blue; $\mathrm{SC}$, superior colliculus; $\mathrm{CnF}$, cuneiform nucleus; LPB, lateral parabrachial nucleus; IC, inferior colliculus; 11, lateral lemniscus; scale bar, $200 \mu \mathrm{m})$. (C) Measured velocity aligned to flight onset at two different frequencies ( $\mathrm{N}=$ number of trials, 1 trial per animal). (D) Latency to initiate flight from stimulation onset showed no significant difference between low and high frequency (blue dots represent individual subjects). (E) Representative example of escape to the shelter upon stimulation in a ChR2-expressing animal ( $\mathrm{t}=0$ indicates stimulation onset). (F) ChR2-expressing animals showed significantly lower latency to escape in the shelter upon stimulation compared to control animals $(\mathrm{N}=4$; two-tailed unpaired $\mathrm{t}$ test, $\mathrm{t}(6)=-3.63, * \mathrm{P}=0.0110)$

\section{Discussion}

Earlier cell-type specific optogenetic stimulation studies established that excitatory, but not inhibitory neurons in $\mathrm{dPAG}$ elicited flight behavior and here we have confirmed these findings and extended them to demonstrate that this behavior is directed toward a familiar shelter and can be elicited by a subset of dPAG neurons that project to CnF. Furthermore, we have used multiplex in situ sequencing to colocalize a set of selected marker genes in dPAG to define subsets of excitatory neurons (Nos $1+$ vs. Tac $2+$ vs. non-Nos $1+/ T a c 2+)$ and used cell-type specific optogenetic activation to test their functional capacity to drive flight behavior. Our findings show that two major excitatory neuronal cell-types in $\mathrm{dPAG}-$ marked by Nos 1 and Tac 2 co-expression - are not able to drive flight behavior, at least when activated alone, suggesting that the remaining non-Nos $1+/ \mathrm{Tac} 2+$ subpopulation is the key driver of flight. The finding that optogenetic activation of Nos $1+$ cells in $\mathrm{dPAG}$ is not sufficient to elicit defensive behavior is somewhat surprising given that pharmacological 
activation or inhibition of nitric-oxide synthase increases and decreases defensive responses to predator (Hall \& Behbehani, 1998; Braga et al., 2009). However, the lack of spontaneous flight behavior upon optogenetic activation does not rule out that these cells are nevertheless involved in the modulation of defensive responses elicited by a natural threat and we interpret our findings to suggest only that Nos $1+$ cells are unlikely to include dPAG projection cells that drive the activation of downstream locomotor initiation centers. We note that, although Tac2+ cells in $\mathrm{dPAG}$ were not implicated in defensive behaviors here, stimulation of $\mathrm{Tac} 2+$ cells in forebrain regions have been shown to elicit avoidance (Zelikowsky et al., 2018). Our findings leave open the question of the role of Tac2+ cells and the dmPAG more generally in defensive behavior. We note for example that dmPAG is a direct target of frontal cortical inputs that are known to inhibit defensive responses to threat (Franklin et al., 2017; Fillinger et al., 2018). Again, our optogenetic stimulation approach was not able to determine whether Tac2+ cells might be involved in the modulation of flight - for example, via its sensory-dependent triggering, disinhibition, or termination.

A major finding of our work is that projections from dPAG to $\mathrm{CnF}$ were able to elicit goal-directed flight behavior. Optogenetic stimulation of $\mathrm{CnF}$ neurons is known to elicit high-speed locomotion and projections from $\mathrm{dPAG}$ to $\mathrm{CnF}$ had been suspected to mediate dPAG-dependent flight behavior (Chang et al., 2020). Our findings confirm this hypothesis. Critically, the observation that animals in which CnF-projecting neurons in dPAG were optogenetically stimulated showed robust goal-directed flight suggests that critical spatial information required for remembering, orienting to, and actively tracking shelter position reaches the defensive escape pathway downstream of dPAG, possibly as a result of converging afferents from sensory-receptive areas in superior and inferior colliculus and cortex in the MLR. Future work on the functional integration of dPAG projections to $\mathrm{CnF}$ and downstream locomotor areas such as LPGi (Capelli et al., 2017) will be needed to understand how high-speed escape is modulated to guide the animal to safety and how this is coordinated with cortical inputs contributing associative models of the environment. 


\section{Materials \& Methods}

\section{Mice}

All experimental subjects were adult male C57BL/6 mice obtained from local EMBL or EMMA colonies or from Charles River Laboratories (Calco, Italy). For cell-type specific optogenetic manipulation Vglut2::Cre (Borgius et al., 2010), PACAP::Cre (Krashes et al., 2014), Tac2::Cre (Mar, Yang, \& Ma, 2012), Gad2::Cre (Taniguchi et al., 2011) and Nos1::CreERT2 (Taniguchi et al., 2011) were used. Where necessary mice were treated with tamoxifen for five consecutive days during the second week of recovery from surgery (Sigma, $40 \mathrm{mg} / \mathrm{kg}$ i.p.). All mice were genotyped before experimentation. For retrograde projection activation wild-type mice were used. Mice were maintained in a temperature $\left(22 \pm 1{ }^{\circ} \mathrm{C}\right)$ and humidity-controlled $(50 \% \mathrm{rH})$ facility on a $12 \mathrm{~h}$ light-dark cycle (lights on at 07:00) with food and water provided ad libitum.

\section{Animal surgery}

Isoflurane (induction 3\%, maintenance 1.5\%; Provet) in oxygen-enriched air was used to anaesthetize mice fixed in a stereotactic frame (Kopf Instruments). All mice received a subcutaneous injection of $1 \%$ Caprofen solution $(5 \mathrm{mg} / \mathrm{kg}$ Rymadil, $0.01 \mathrm{ml} / \mathrm{g}$ ) for surgical analgesia. For cell-type specific activation, Vglut2::Cre, Adcyap 1::Cre, Tac2::Cre and Nos $1::$ Cre, Gad2::Cre transgenic mice were infused bilaterally in dPAG (AP:-4.24, $\mathrm{L}: \pm 0.30$, DV:-2.15 from Bregma) with 60-120 nl/side of AAV5-Efla::DIO-hChR2(E123T/T159C)-EYFP virus (UNC Vector Core) for experimental groups or AAV5-Efla::DIO-EYFP virus (UNC Vector Core) for control groups using a pulled glass capillary. In the same surgery mice were unilaterally implanted with custom-built fibre connectors (fibre: 0.66 numerical aperture, $200 \mu \mathrm{m}$ core diameter; ceramic ferrule: $230 \mu \mathrm{m}$ internal diameter, $1.25 \mathrm{~mm}$ outer diameter; Prizmatix) in the dPAG just above the viral infection site (AP:-4.24, L:+0.90, DV:-2.15 from Bregma, at $26^{\circ}$ angle to avoid sigmoid sinus damage). For retrograde afferent activation wild-type mice were injected unilaterally in CnF (AP:-5.7 L: \pm 1.23 , DV:-3.80 from Bregma, with a posterior-anterior $15^{\circ}$ angle) with $180 \mathrm{nl}$ of virus solution composed of AAV-CMV::Hi.eGFP-Cre (Penn Vector Core) mixed with AAV-eSyn::iRFP670 as a marker for the site of injection (UNC Vector Core) at a ratio of $4: 1$. In the same surgery animals 
were unilaterally injected in the dPAG with $180 \mathrm{nl}$ of

AAV5-Efla::DIO-hChR2(E123T/T159C)-EYFP and AAV5-hSyn::DIO-mCherry as a marker for the site of injection (UNC Vector Core) at 4:1 ratio. Mice in the control group were injected, using the same coordinates, with AAV5-Ef1a::DIO-EYFP and AAV5-hSyn::DIO-mCherry in a ratio of 4:1. The dPAG injection was performed by insertion of the capillary in the contralateral hemisphere of the target area with a $28^{\circ}$ mediolateral angle (AP: -4.24 , ML: +0.85 , DV: -2.30 from Bregma) to avoid infection of the ipsilateral superior colliculus. The optic fibre (0.22 numerical aperture, $225 \mu \mathrm{m}$ core diameter; ceramic ferrule: $1.25 \mathrm{~mm}$ outer diameter; Thorlabs) was implanted unilaterally over the ipsilateral dPAG (AP: -4.24 , ML: -1.45 , DV: -2.00 from Bregma with a $26^{\circ}$ mediolateral angle). In both the cell-type specific dPAG activation experiment and the retrograde projection activation experiment injections were at a rate of approximately 60 $\mathrm{nl} / \mathrm{min}$. At the end of surgical procedures animals were injected with $1 \mathrm{ml}$ saline (i.p.) and remained on a controlled temperature heating pad overnight. Animals were given paracetamol $(0.8 \mathrm{mg} / \mathrm{ml}$, Tachipirina) in the drinking water for 3 days and monitored for one week to assess normal recovery. After surgical procedure mice were singly housed to avoid implant damage due to conspecific interactions.

\section{Optogenetic stimulation}

In the cell-type specific dPAG activation experiments optical stimulation of ChR2-expressing cells was carried out by delivery of blue light (465 nm) from LED modules attached to a rotary joint via high performance patch cables (Plexbright, Plexon). All stimulation trains were generated with Radiant V2.2 (Plexon). For optical stimulation of ChR2-expressing cells in the retrograde projection activation experiment, blue (465 $\mathrm{nm})$ laser light (PSU-III-LED, Thorlabs) was applied. Light was delivered from the laser via high performance patch cables (Thorlabs); all stimulation trains were generated with Pulser Software. Stimulation pulse width duration was fixed at $15 \mathrm{~ms}$. Power intensities and frequencies for the experimental group were picked for each subject as the minimum value evoking the optimal behavioral response (sudden burst of locomotor activity, 10-20 mW). Control animals were stimulated at the highest power and frequency $(10 \mathrm{~mW}, 20 \mathrm{~Hz}$ for cell-type specific dPAG activation; $20 \mathrm{~mW}, 40 \mathrm{~Hz}$ for retrograde projection activation).

\section{Behavior}


All behavioral experiments were performed on mice at least 8 weeks old. Behavioral tests were performed 3-4 weeks after surgery. All behavioral testing occurred during animals' light cycle. All behavioral videos were recorded with a top view camera and Biobserve Viewer under ambient lighting. Animals were handled for at least 2 days before the start of any behavioral assay. All mice were handled according to protocols approved by the Italian Ministry of Health (\#137/2011-B, \#231/2011-B and \#541/2015-PR) and commensurate with NIH guidelines for the ethical treatment of animals.

Locomotion assay - To assay overt locomotor behavior in response to optogenetic stimulation mice were attached to optical patch cables and placed in a novel transparent plexiglass chamber $(24 \times 24 \times 24 \mathrm{~cm})$ and allowed to habituate for $5 \mathrm{~min}$. After the habituation phase, Vglut2::Cre and PACAP::Cre mice infected in dPAG with ChR2-expressing AAV (AAV-Ef1a::DIO-CHR2-YFP) and implanted with optic fibers above the infection site, received $1 \mathrm{~s}$ long light stimulation followed by a $60 \mathrm{~s}$ inter-stimulation interval. Stimulation intensity was selected according to an increasing pattern $(2 / 5 / 10 \mathrm{~mW})$ each applied at $5 / 10 / 20 / 40 \mathrm{~Hz}$ in an increasing sequence. Each stimulation combination was repeated five times. Because no overt locomotor response was detected in Tac2::Cre, Nos $1::$ Cre, and Gad2::Cre mice stimulation lasted $120 \mathrm{~s}$ at each intensity and frequency, followed by $120 \mathrm{~s}$ inter-stimulus interval in order to assess any potential subtle responses or long-term post-stimulation effects. Each stimulation condition was repeated five times. For retrograde projection activation stimulation lasted $1 \mathrm{~s}$ at each intensity and frequency, followed by $60 \mathrm{~s}$ inter-stimulus interval. Stimulation intensity followed an increasing pattern $(0.5-25 \mathrm{~mW})$ applied at $20 \mathrm{~Hz}$ and then, from $10 \mathrm{~mW}$, repeated at $40 \mathrm{~Hz}$.

Goal-directed escape assay - Animals were placed in a transparent plexiglass chamber $(24 \times 24 \times 24 \mathrm{~cm})$ with a shelter $(18 \times 7 \times 13 \mathrm{~cm}$ cardboard box with large opening on one side) placed in a corner. The shelter floor was lined with the animal's home cage bedding. Animals were free to explore and habituate for $5 \mathrm{~min}$ or until they displayed no reluctance to enter the shelter. After habituation, light was delivered at varying intensity and frequency $(10 \mathrm{~mW}, 20 \mathrm{~Hz}$ for dPAG Vglut2::Cre activation; 10-20 mW, $40 \mathrm{~Hz}$ for retrograde projection activation) when the animal was outside the shelter and at the far side 
of the cage and persisted until the animal entered the shelter. The procedure was repeated 3-6 times.

Real time place preference - Animals were placed in an apparatus composed of two chambers (each $24 \times 24 \times 24 \mathrm{~cm}$ ) connected by a door $(3 \mathrm{~cm}$ width) and were free to access both chambers for ten minutes. At the end of the habituation phase the preferred chamber was selected as the stimulation chamber and for the following 10 minutes the animal was stimulated $(10 \mathrm{~mW}, 20 \mathrm{~Hz})$ whenever it entered that chamber. If the animal remained in the chamber for more than $90 \mathrm{~s}$ the stimulation was terminated for $30 \mathrm{~s}$ before initiating another $90 \mathrm{~s}$ stimulation bout. Stimulation was terminated upon exit from the chamber.

\section{Afferent mapping with CTB}

For identification of projection neurons in PAG, Vglut2::Cre or Gad2::Cre mice were injected bilaterally in $\mathrm{APAG}$ with AAV-hSyn::DIO-mCherry (150 $\mathrm{nl}$ each side) and after one week injected with $60 \mathrm{nl}$ 0.5\% CTB-488 (Thermo Fisher \#C34775) unilaterally into the $\mathrm{CnF}$ (AP: $-4.90, \mathrm{~L}: 1.23, \mathrm{DV}:-3.00$ from Bregma) and the capillary left in place for at least 10 min to avoid CTB spread along the injection tract. Animals were perfused one week after CTB injection.

\section{In situ sequencing}

CARTANA (10x Genomics) kits were used to process samples for in situ sequencing following manufacturer instructions. CARTANA were provided a list of genes and designed and provided the padlock probes. Imaging of fluorescent samples was carried out with an X-light V3 spinning disk (Crest Optics) coupled to a Nikon Ti inverted microscope (Nikon), a Prime BSI sCMOS camera (Photometrics), and a Celesta laser light engine (Lumencor). Images were acquired in 5 channels using excitations at 405, 477, 546, 638 and $749 \mathrm{~nm}$. Appropriate filters for DAPI, GFP, Cy3, Cy5 and Cy7 were used. Imaging was done using a 20x NA 0.8 Nikon objective. Z-stacks over the region of interest were acquired using a custom JOB program created in Nikon NIS Elements. Z-stacks were converted to a single image by maximum intensity projection within NIS Elements. Image registration was done in two steps, using custom tools in MATLAB (The Mathworks). First, a coarse registration was performed by fast Fourier transform using a downscaled image of the DAPI channel. Then, full resolution images were registered using the 
intensity and the image of the dots themselves in squared tiles of 500 pixels and re-stitched together. Decoding was performed using the ISTDECO algorithm that combines spectral and spatial information to decode the identity and position of transcripts. Two fake codes were included in the codebook to control for possible artifacts. Fake codes comprised less than $2 \%$ of all decoded spots. We used squared tiles of 500 pixels, a PSF size of 2 , an intensity percentile value of 99.95 and a quality threshold of 0.5 . Resulting gene expression signals (spots) were thresholded (quality score $>2$ ) and only those spots falling within expanded, but well segregated DAPI-defined areas (manually selected; dotted lines in Fig. 1B) were retained for co-expression analysis. An arbitrary cutoff of two spots was used to call gene expression for estimating cell-types; Gad2 and Vgat signal were collapsed before scoring spots for GABAergic identity. Map2 and Grin2b were not used in co-expression analysis. A mask based on macroscopic DAPI staining and brain atlas boundaries was used to restrict the analysis to dPAG. Both hemispheres of the brain section were used for co-expression analysis, although only one half is shown in Fig. 1A.

\section{Histology and Microscopy}

Mice were transcardially perfused with PBS followed by 4\% paraformaldehyde in PB. Brains were left to postfix overnight in $4 \%$ PFA at $4{ }^{\circ} \mathrm{C}$. Brains were either sectioned in PBS with a vibratome (Leica VT1000s) or cryo-sectioned. For cryo-sectioning brains were first briefly rinsed in PBS after post-fixation, then left in 30\% sucrose in PBS for 2 days before flash freezing in pre-chilled isopentane. Frozen brains were sectioned on a cryostat (Leica CM3050s). Sections of 50 or $70 \mu \mathrm{m}$ were taken from the areas of interest. DAPI (5 $\mathrm{mg} / \mathrm{ml}$ ) was added directly to the mounting medium (MOWIOL). Widefield images were acquired with a Leica LMD5 microscope; confocal images were acquired with a Leica SP5 with resonant scanning. Optic fibre placements and injection sites were verified according to anatomical landmarks and an atlas (Franklin and Paxinos, 2008) and widefield images (Leica LMD5). Mice with incorrect fibre position or unsuccessful viral infection were excluded from the analysis.

\section{Data analysis}

Behavioral data were obtained with either manual scoring software (Solomon Coder) or automatic scoring software (Biobserver Viewer and Bonsai). For manual scoring flight was defined as a "sudden burst in velocity". 


\section{Statistics}

All statistical analysis was performed using Prism 7 (GraphPad). All p-values were adjusted and error bars were mean \pm SEM unless otherwise noted. Group differences were determined using multiple t-test with Holm-Sidak post hoc tests, Mann-Whitney unpaired t-test, or two-way ANOVA with Tukey's post hoc testing.

\section{Acknowledgements}

We thank Francesca Zonfrillo, Claudia Valeri, Roberto Voci, and Valerio Rossi for support with animal husbandry and management, Quifu Ma for sharing Tac2::Cre mice, and Angelo Raggioli for support with production of viruses and the EMBL Microscopy, Histology, Gene Editing \& Embryology, and Laboratory Animal Facilities for support. The work was supported by EMBL and the European Research Council (ERC) Advanced Grant COREFEAR to C.T.G.

\section{Author contributions}

Multiplex gene expression analysis was carried out by A.C. and E.P. and gene-co-expression data analysis executed by R.S. Behavioral experiments and their analysis were carried out by E.T, C.O., M.E.M. and I.P. The project was conceived by E.T. and C.T.G., who designed the experiments. C.T.G wrote the manuscript with input from C.O. and M.E.M.

\section{References}

1. Amano K, Tanikawa T, Iseki H, Kawabatake H, Notani M, Kawamura H, Kitamura K. Single neuron analysis of the human midbrain tegmentum. Rostral mecencephalic reticulotomy for pain relief. Appl Neurophysiol. 1978;41(1-4):66-78. doi: 10.1159/000102402. PMID: 727773.

2. Asp M, Bergenstråhle J, Lundeberg J. Spatially Resolved Transcriptomes-Next Generation Tools for Tissue Exploration. Bioessays. 2020 Oct;42(10):e1900221. doi: 10.1002/bies.201900221. Epub 2020 May 4. PMID: 32363691.

3. Behbehani MM. Functional characteristics of the midbrain periaqueductal gray. Prog Neurobiol. 1995 Aug;46(6):575-605. doi: 10.1016/0301-0082(95)00009-k. PMID: 8545545 . 
4. Bittencourt AS, Carobrez AP, Zamprogno LP, Tufik S, Schenberg LC. Organization of single components of defensive behaviors within distinct columns of periaqueductal gray matter of the rat: role of N-methyl-D-aspartic acid glutamate receptors. Neuroscience. 2004;125(1):71-89. doi: 10.1016/j.neuroscience.2004.01.026. PMID: 15051147.

5. Braga AA, Aguiar DC, Guimarães FS. NOC-9, a selective nitric oxide donor, induces flight reactions in the dorsolateral periaqueductal gray of rats by activating soluble guanylate cyclase. Neurosci Lett. 2009 Aug 7;459(2):79-83. doi:

10.1016/j.neulet.2009.05.009. Epub 2009 May 7. PMID: 19427360.

6. Caggiano V, Leiras R, Goñi-Erro H, Masini D, Bellardita C, Bouvier J, Caldeira V, Fisone G, Kiehn O. Midbrain circuits that set locomotor speed and gait selection. Nature. 2018 Jan 25;553(7689):455-460. doi: 10.1038/nature25448. Epub 2018 Jan 17. PMID: 29342142; PMCID: PMC5937258.

7. Chang SJ, Cajigas I, Opris I, Guest JD and Noga BR (2020) Dissecting Brainstem Locomotor Circuits: Converging Evidence for Cuneiform Nucleus Stimulation. Front. Syst. Neurosci. 14:64. doi: 10.3389/fnsys.2020.00064. Epub 2020 August 21.

8. Canteras NS, Simerly RB, Swanson LW. Projections of the ventral premammillary nucleus. J Comp Neurol. 1992 Oct 8;324(2):195-212. doi: 10.1002/cne.903240205. PMID: 1430329.

9. Canteras NS, Swanson LW. Projections of the ventral subiculum to the amygdala, septum, and hypothalamus: a PHAL anterograde tract-tracing study in the rat. J Comp Neurol. 1992 Oct 8;324(2):180-94. doi: 10.1002/cne.903240204. PMID: 1430328.

10. Canteras NS, Simerly RB, Swanson LW. Organization of projections from the ventromedial nucleus of the hypothalamus: a Phaseolus vulgaris-leucoagglutinin study in the rat. J Comp Neurol. 1994 Oct 1;348(1):41-79. doi: 10.1002/cne.903480103. PMID: 7814684.

11. Capelli P, Pivetta C, Soledad Esposito M, Arber S. Locomotor speed control circuits in the caudal brainstem. Nature. 2017 Nov 16;551(7680):373-377. doi: 10.1038/nature24064. Epub 2017 Oct 23. PMID: 29059682.

12. Deng H, Xiao X, Wang Z. Periaqueductal Gray Neuronal Activities Underlie Different Aspects of Defensive Behaviors. J Neurosci. 2016 Jul 20;36(29):7580-8. doi: 10.1523/JNEUROSCI.4425-15.2016. PMID: 27445137; PMCID: PMC6705556. 
13. Depaulis, A., Keay, K.A. \& Bandler, R. Longitudinal neuronal organization of defensive reactions in the midbrain periaqueductal gray region of the rat. Exp Brain Res 90, 307-318 (1992). https://doi.org/10.1007/BF00227243

14. Dielenberg RA, Hunt GE, McGregor IS. "When a rat smells a cat": the distribution of Fos immunoreactivity in rat brain following exposure to a predatory odor. Neuroscience. 2001;104(4):1085-97. doi: 10.1016/s0306-4522(01)00150-6. PMID: 11457592.

15. Evans DA, Stempel AV, Vale R, Ruehle S, Lefler Y, Branco T. A synaptic threshold mechanism for computing escape decisions. Nature. 2018 Jun;558(7711):590-594. doi: 10.1038/s41586-018-0244-6. Epub 2018 Jun 20. PMID: 29925954; PMCID: PMC6235113.

16. Fanselow M.S. (1991) The Midbrain Periaqueductal Gray as a Coordinator of Action in Response to Fear and Anxiety. In: Depaulis A., Bandler R. (eds) The Midbrain Periaqueductal Gray Matter. NATO ASI Series (Series A: Life Sciences), vol 213. Springer, Boston, MA. https://doi.org/10.1007/978-1-4615-3302-3 10

17. Fillinger C, Yalcin I, Barrot M, Veinante P. Efferents of anterior cingulate areas 24a and 24b and midcingulate areas 24a' and 24b' in the mouse. Brain Struct Funct. 2018 May;223(4):1747-1778. doi: 10.1007/s00429-017-1585-x. Epub 2017 Dec 6. PMID: 29209804.

18. Franklin, T., Silva, B., Perova, Z. et al. Prefrontal cortical control of a brainstem social behavior circuit. Nat Neurosci 20, 260-270 (2017). https://doi.org/10.1038/nn.4470

19. Gross, C., Canteras, N. The many paths to fear. Nat Rev Neurosci 13, 651-658 (2012). https://doi.org/10.1038/nrn3301

20. Hall CW, Behbehani MM. Synaptic effects of nitric oxide on enkephalinergic, GABAergic, and glutamatergic networks of the rat periaqueductal gray. Brain Res. 1998 Sep 14;805(1-2):69-87. doi: 10.1016/s0006-8993(98)00648-9. PMID: 9733923.

21. Hower Lee, Sergio Marco Salas, Daniel Gyllborg, Mats Nilsson. Direct RNA targeted transcriptomic profiling in tissue using Hybridization-based RNA In Situ Sequencing (HybRISS) bioRxiv 2020.12.02.408781; doi:

https://doi.org/10.1101/2020.12.02.408781

22. Krashes MJ, Shah BP, Madara JC, Olson DP, Strochlic DE, Garfield AS, Vong L, Pei H, Watabe-Uchida M, Uchida N, Liberles SD, Lowell BB. An excitatory 
paraventricular nucleus to AgRP neuron circuit that drives hunger. Nature. $2014 \mathrm{Mar}$ 13;507(7491):238-42. doi: 10.1038/nature12956. Epub 2014 Feb 2. PMID: 24487620; PMCID: PMC3955843.

23. LeDoux J. Rethinking the emotional brain. Neuron. 2012 Feb 23;73(4):653-76. doi: 10.1016/j.neuron.2012.02.004. Erratum in: Neuron. 2012 Mar 8;73(5):1052. PMID: 22365542 ; PMCID: PMC3625946.

24. Lein E, Borm LE, Linnarsson S. The promise of spatial transcriptomics for neuroscience in the era of molecular cell typing. Science. 2017 Oct 6;358(6359):64-69. doi: 10.1126/science.aan6827. PMID: 28983044.

25. Masferrer, M. E., B. A. Silva, K. Nomoto, S. Q. Lima, and C. T. Gross. 2018. Differential Encoding of Predator Fear in the Ventromedial Hypothalamus and Periaqueductal Grey. Journal of Neuroscience 25 November 2020, 40 (48) 9283-9292; DOI: 10.1523/JNEUROSCI.0761-18.2020

26. MATLAB. version 7.10.0 (R2010a). Natick, Massachusetts: The MathWorks Inc; 2010 .

27. Meller ST, Dennis BJ. Efferent projections of the periaqueductal gray in the rabbit. Neuroscience. 1991;40(1):191-216. doi: 10.1016/0306-4522(91)90185-q. PMID: 1646974.

28. Mobbs D. The ethological deconstruction of fear(s). Curr Opin Behav Sci. 2018 Dec;24:32-37. doi: 10.1016/j.cobeha.2018.02.008. Epub 2018 Mar 20. PMID: 31467943; PMCID: PMC6715320.

29. Mobbs D, Petrovic P, Marchant JL, Hassabis D, Weiskopf N, Seymour B, Dolan RJ, Frith CD. When fear is near: threat imminence elicits prefrontal-periaqueductal gray shifts in humans. Science. 2007 Aug 24;317(5841):1079-83. doi: 10.1126/science.1144298. PMID: 17717184; PMCID: PMC2648508.

30. Nashold BS Jr, Wilson WP, Slaughter DG. Sensations evoked by stimulation in the midbrain of man. J Neurosurg. 1969 Jan;30(1):14-24. doi: 10.3171/jns.1969.30.1.0014. PMID: 4885810.

31. Redgrave P, Dean P, Mitchell IJ, Odekunle A, Clark A. The projection from superior colliculus to cuneiform area in the rat. I. Anatomical studies. Exp Brain Res. 1988;72(3):611-25. doi: 10.1007/BF00250606. PMID: 2466683. 
32. Risold PY, Canteras NS, Swanson LW. Organization of projections from the anterior hypothalamic nucleus: a Phaseolus vulgaris-leucoagglutinin study in the rat. J Comp Neurol. 1994 Oct 1;348(1):1-40. doi: 10.1002/cne.903480102. PMID: 7814679.

33. Rizvi TA, Ennis M, Shipley MT. Reciprocal connections between the medial preoptic area and the midbrain periaqueductal gray in rat: a WGA-HRP and PHA-L study. J Comp Neurol. 1992 Jan 1;315(1):1-15. doi: 10.1002/cne.903150102. PMID: 1371779.

34. Rossier D, La Franca V, Salemi T, Natale S, Gross CT. A neural circuit for competing approach and defense underlying prey capture. Proc Natl Acad Sci U S A. 2021 Apr 13;118(15):e2013411118. doi: 10.1073/pnas.2013411118. PMID: 33876745; PMCID: PMC8053977.

35. Sandner, G., di Scala, G., Rocha, B., \& Angst, M. J. (1992). C-fos immunoreactivity in the brain following unilateral electrical stimulation of the dorsal periaqueductal gray in freely moving rats. Brain Research, 573(2), 276-283. https://doi.org/10.1016/0006-8993(92)90773-3

36. Silva BA, Mattucci C, Krzywkowski P, Murana E, Illarionova A, Grinevich V, Canteras NS, Ragozzino D, Gross CT. Independent hypothalamic circuits for social and predator fear. Nat Neurosci. 2013 Dec;16(12):1731-3. doi: 10.1038/nn.3573. Epub 2013 Nov 10. PMID: 24212674; PMCID: PMC4194278.

37. Silva C, McNaughton N. Are periaqueductal gray and dorsal raphe the foundation of appetitive and aversive control? A comprehensive review. Prog Neurobiol. 2019 Jun;177:33-72. doi: 10.1016/j.pneurobio.2019.02.001. Epub 2019 Feb 17. PMID: 30786258.

38. Simerly RB, Swanson LW. Projections of the medial preoptic nucleus: a Phaseolus vulgaris leucoagglutinin anterograde tract-tracing study in the rat. J Comp Neurol. 1988 Apr 8;270(2):209-42. doi: 10.1002/cne.902700205. PMID: 3259955.

39. Taniguchi H, He M, Wu P, Kim S, Paik R, Sugino K, Kvitsiani D, Fu Y, Lu J, Lin Y, Miyoshi G, Shima Y, Fishell G, Nelson SB, Huang ZJ. A resource of Cre driver lines for genetic targeting of GABAergic neurons in cerebral cortex. Neuron. 2011 Sep 22;71(6):995-1013. doi: 10.1016/j.neuron.2011.07.026. Epub 2011 Sep 21. Erratum in: Neuron. 2011 Dec 22;72(6):1091. Kvitsani, Duda [corrected to Kvitsiani, Duda]. PMID: 21943598; PMCID: PMC3779648. 
40. Thompson RH, Swanson LW. Organization of inputs to the dorsomedial nucleus of the hypothalamus: a reexamination with Fluorogold and PHAL in the rat. Brain Res Brain Res Rev. 1998 Jul;27(2):89-118. doi: 10.1016/s0165-0173(98)00010-1. PMID: 9622601.

41. Todd WD, Fenselau H, Wang JL, Zhang R, Machado NL, Venner A, Broadhurst RY, Kaur S, Lynagh T, Olson DP, Lowell BB, Fuller PM, Saper CB. A hypothalamic circuit for the circadian control of aggression. Nat Neurosci. 2018 May;21(5):717-724. doi: 10.1038/s41593-018-0126-0. Epub 2018 Apr 9. PMID: 29632359; PMCID: PMC5920747.

42. Tovote P, Esposito MS, Botta P, Chaudun F, Fadok JP, Markovic M, Wolff SB, Ramakrishnan C, Fenno L, Deisseroth K, Herry C, Arber S, Lüthi A. Midbrain circuits for defensive behaviour. Nature. 2016 Jun 9;534(7606):206-12. doi: 10.1038/nature17996. Epub 2016 Jun 1. PMID: 27279213.

43. Vargas LC, Marques TA, Schenberg LC. Micturition and defensive behaviors are controlled by distinct neural networks within the dorsal periaqueductal gray and deep gray layer of the superior colliculus of the rat. Neurosci Lett. 2000 Feb 11;280(1):45-8. doi: 10.1016/s0304-3940(99)00985-4. PMID: 10696808.

44. Wiberg M. Reciprocal connections between the periaqueductal gray matter and other somatosensory regions of the cat midbrain: a possible mechanism of pain inhibition. Ups J Med Sci. 1992;97(1):37-47. doi: 10.3109/03009739209179280. PMID: 1523733.

45. Zelikowsky M, Hui M, Karigo T, Choe A, Yang B, Blanco MR, Beadle K, Gradinaru V, Deverman BE, Anderson DJ. The Neuropeptide Tac2 Controls a Distributed Brain State Induced by Chronic Social Isolation Stress. Cell. 2018 May 17;173(5):1265-1279.e19. doi: 10.1016/j.cell.2018.03.037. PMID: 29775595; PMCID: PMC5967263. 


\section{Supplementary Information}

Figure S1. (A-C) Graphical representation of experimental strategy for optogenetic activation of cell-types in dPAG. (B-D) Representative histology showing ChR2 expression (green) and fibre placement for each Cre driver line (solid line; scale bar, $250 \mu \mathrm{m}$ ). 

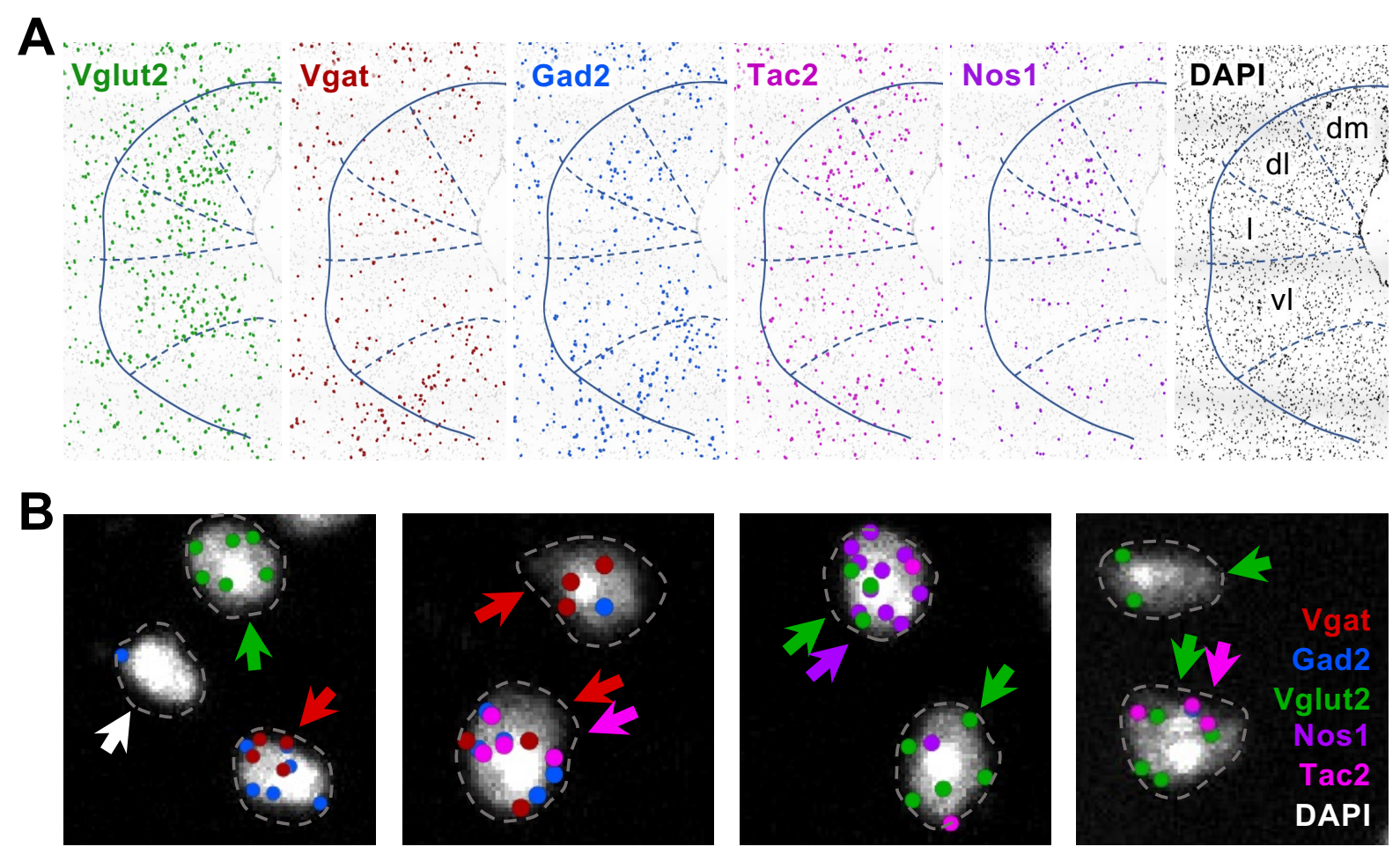

C

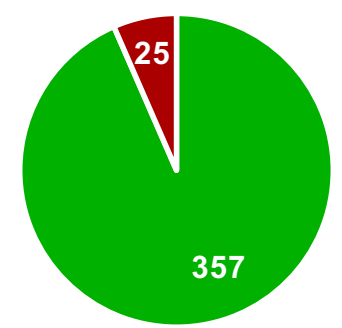

Vglut2+

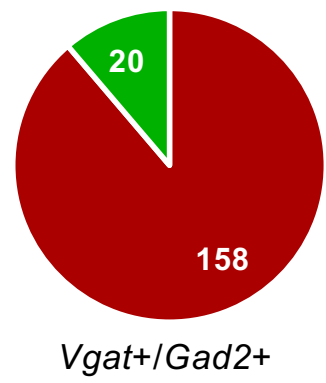

Vgat+/Gad2+

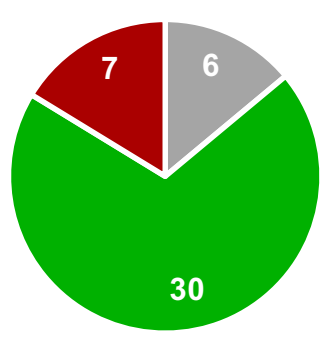

Nos1+

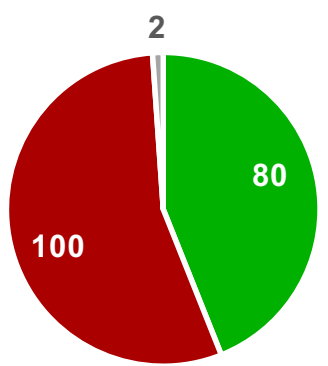

Tac2+ 
A AAV::Ef1a-DIO-ChR2-YFP B

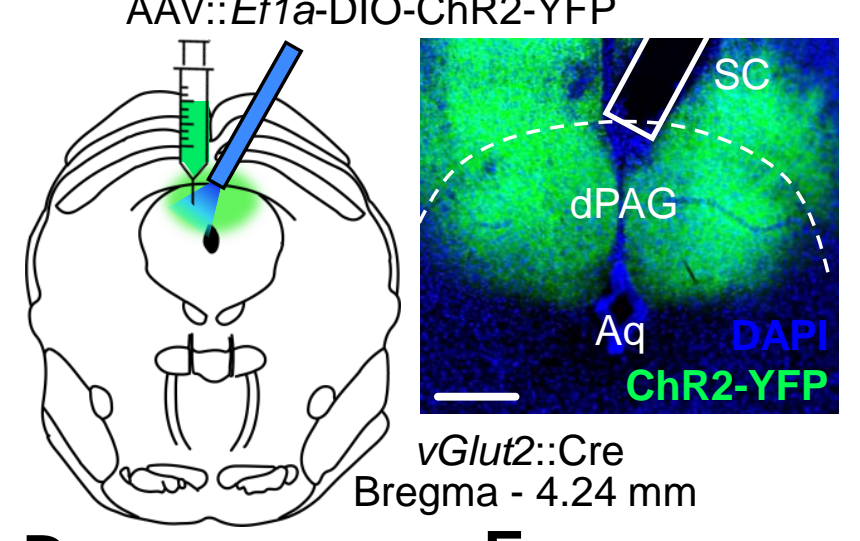

D

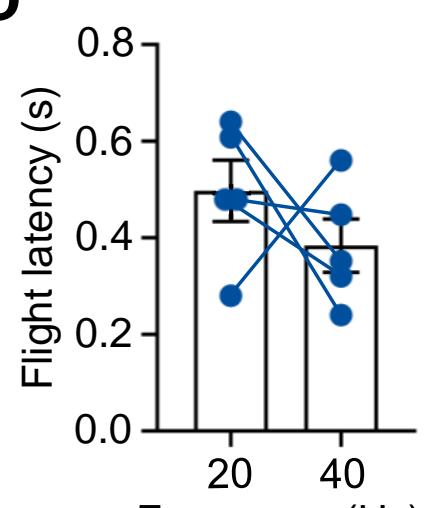

E
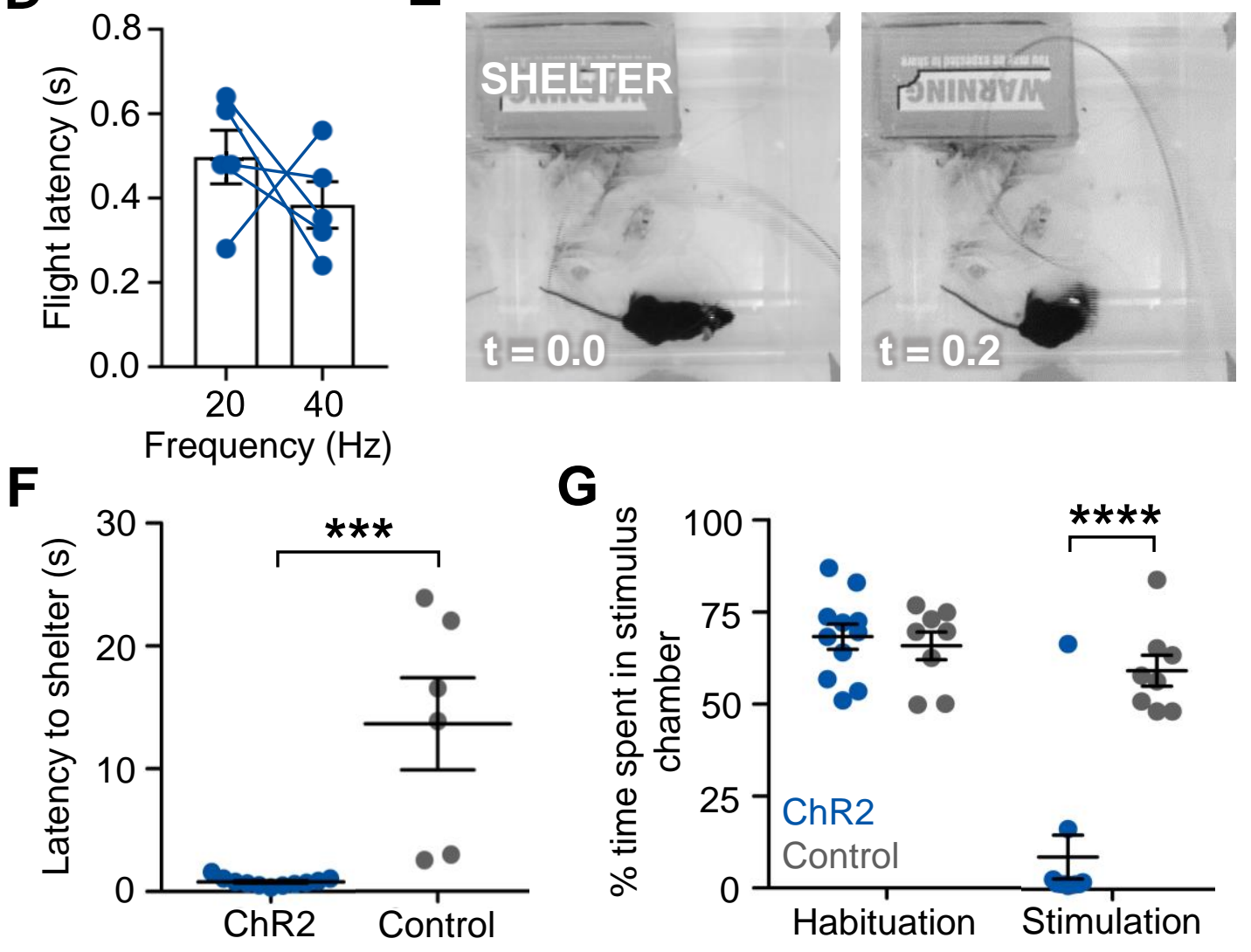

G

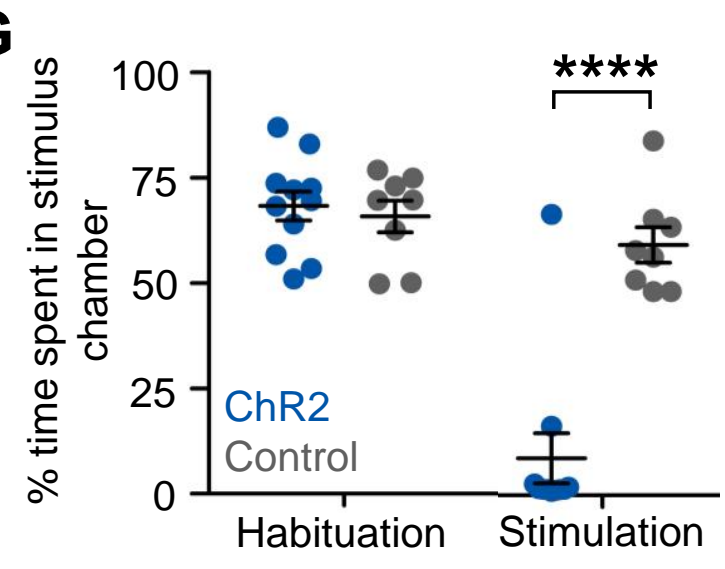

C
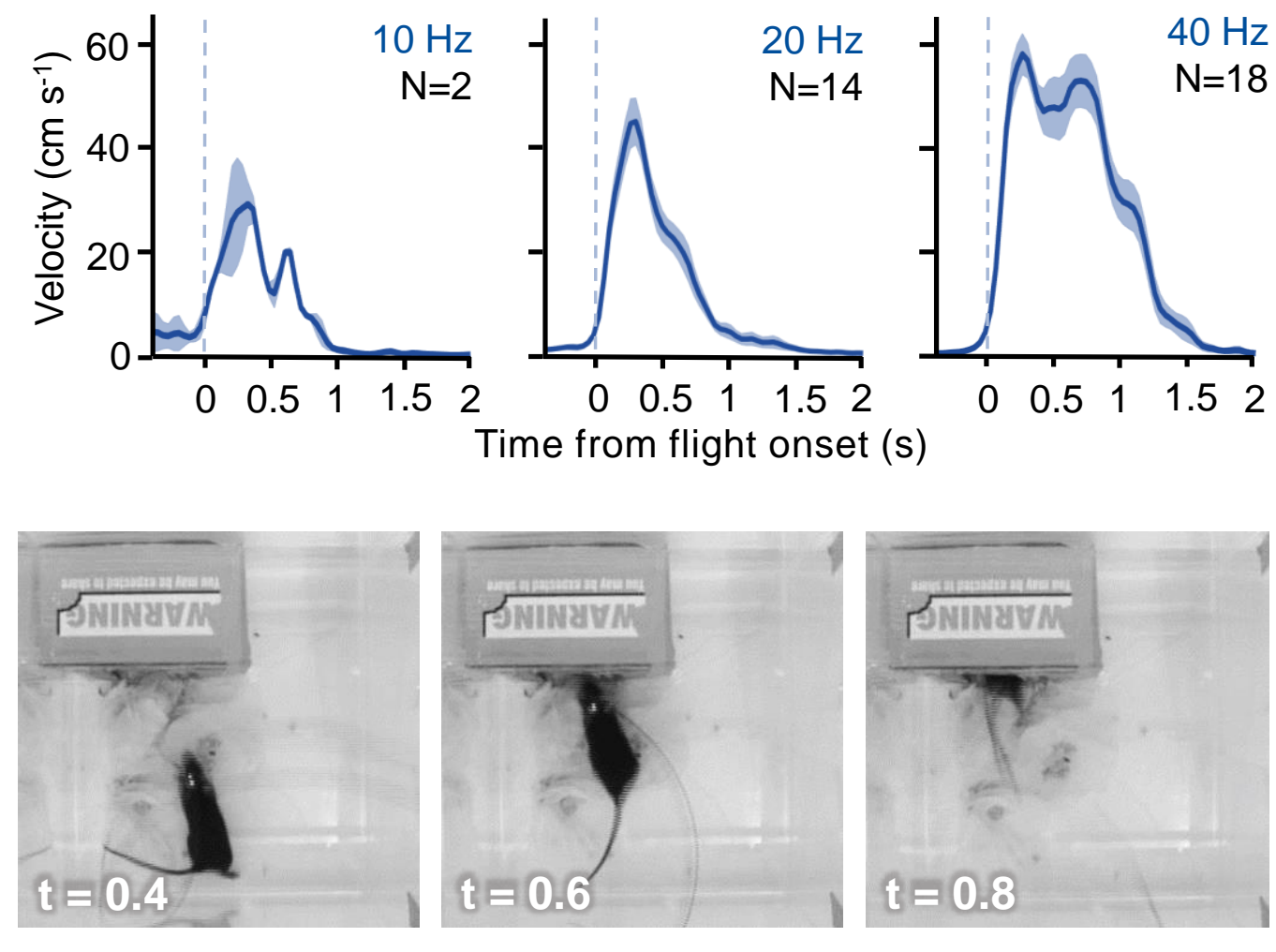

H

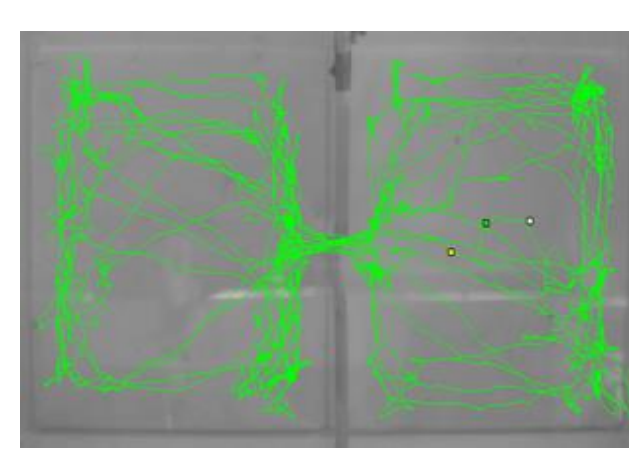

10' Habituation

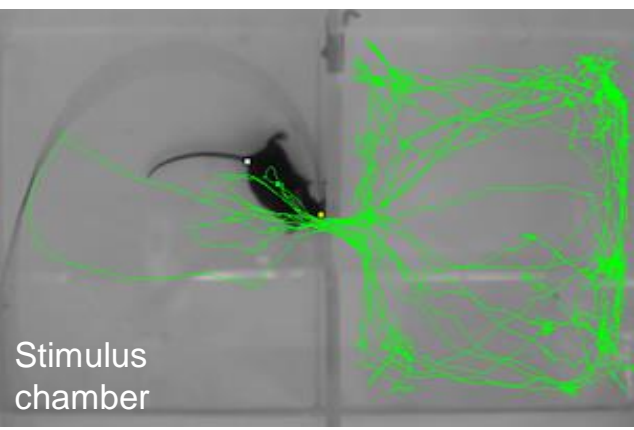

10' Stimulation 
A
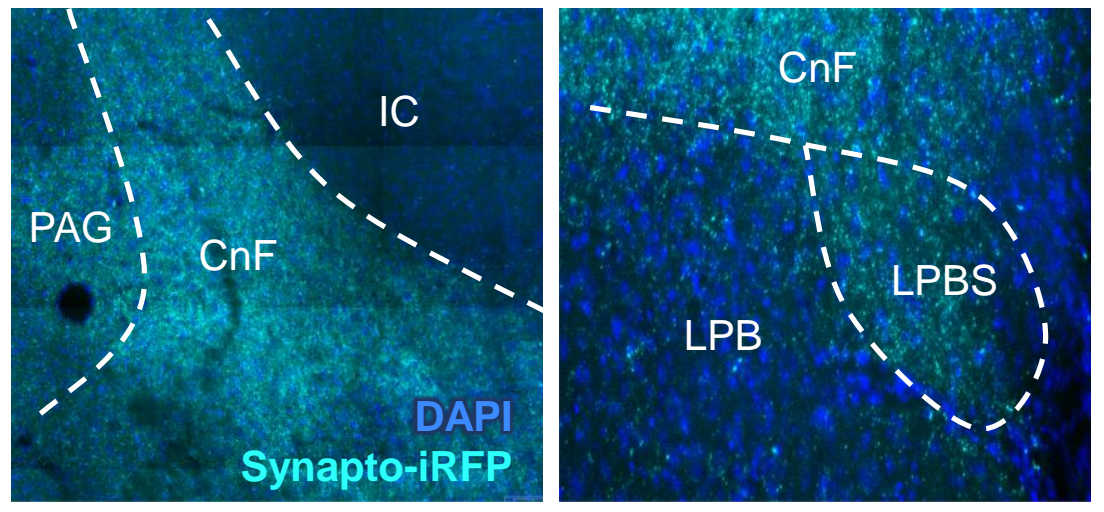

B

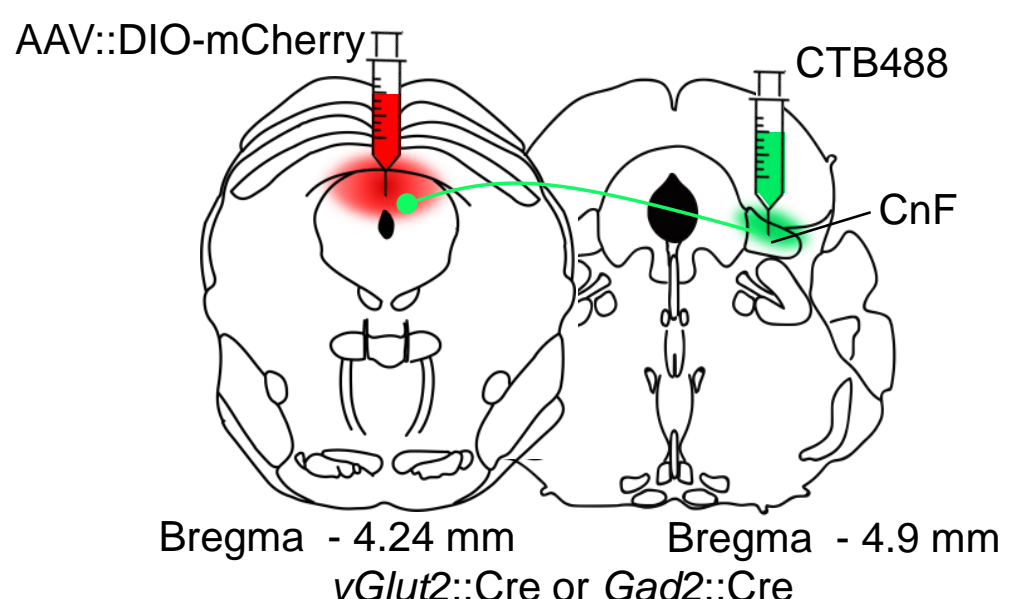

C
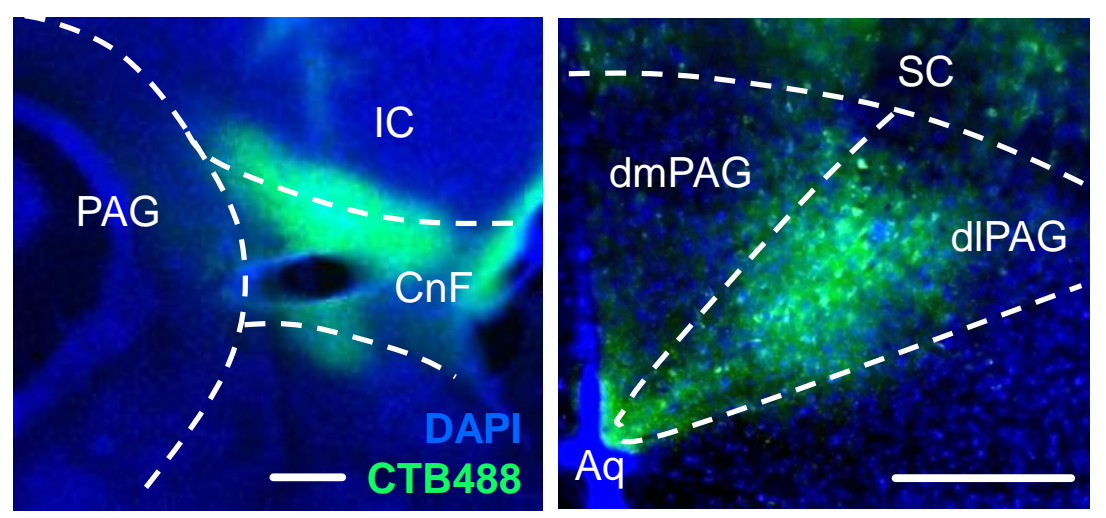

D

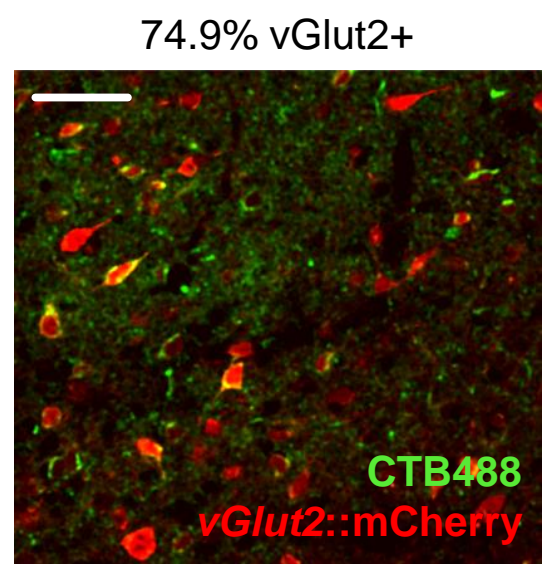

$21.1 \%$ Gad2+

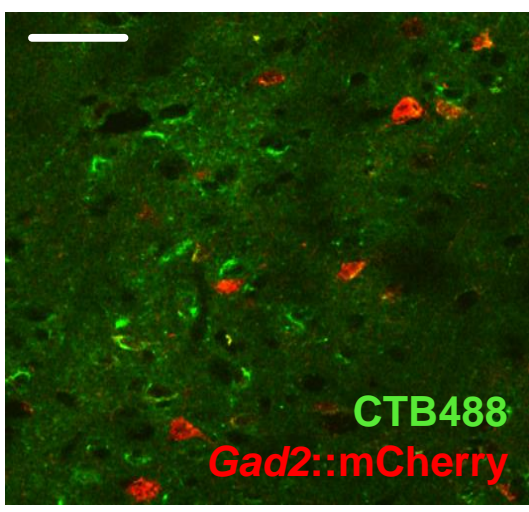


A

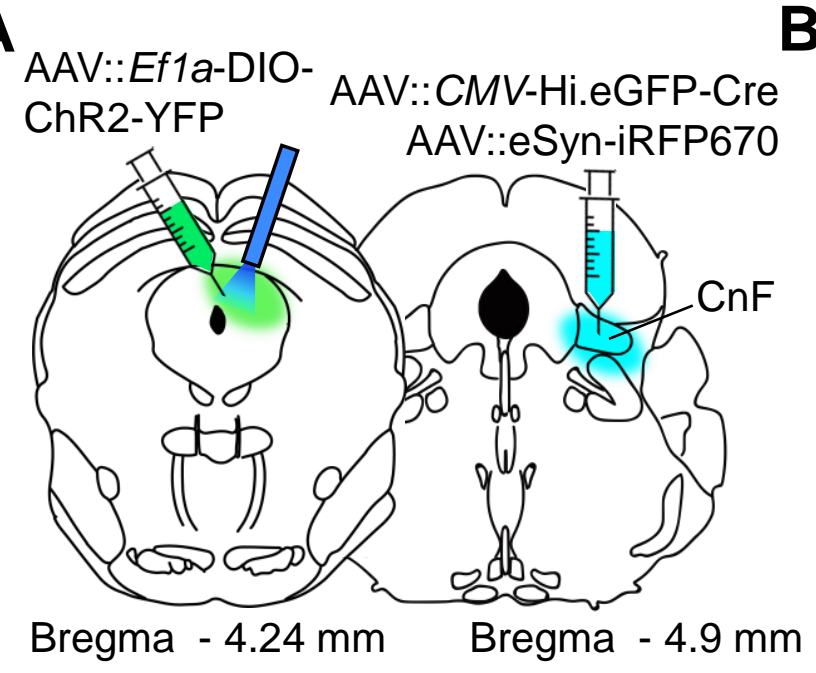

D

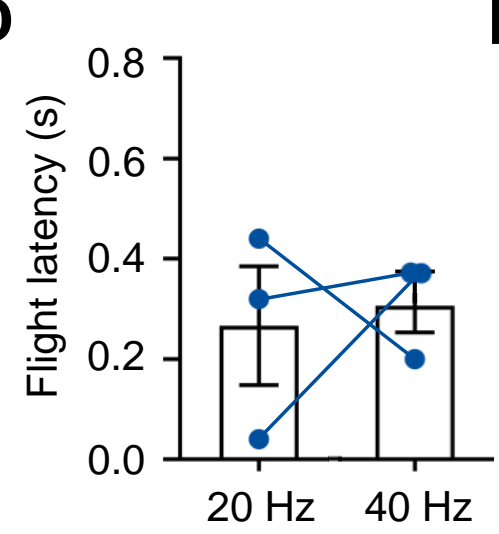

B

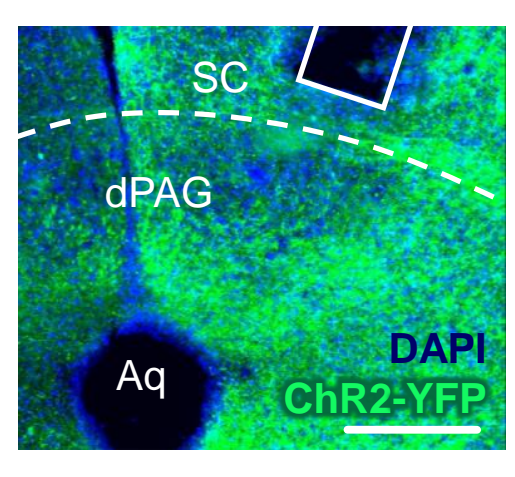

E

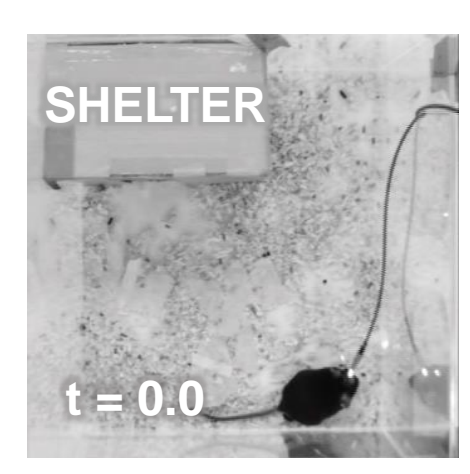

\section{C}
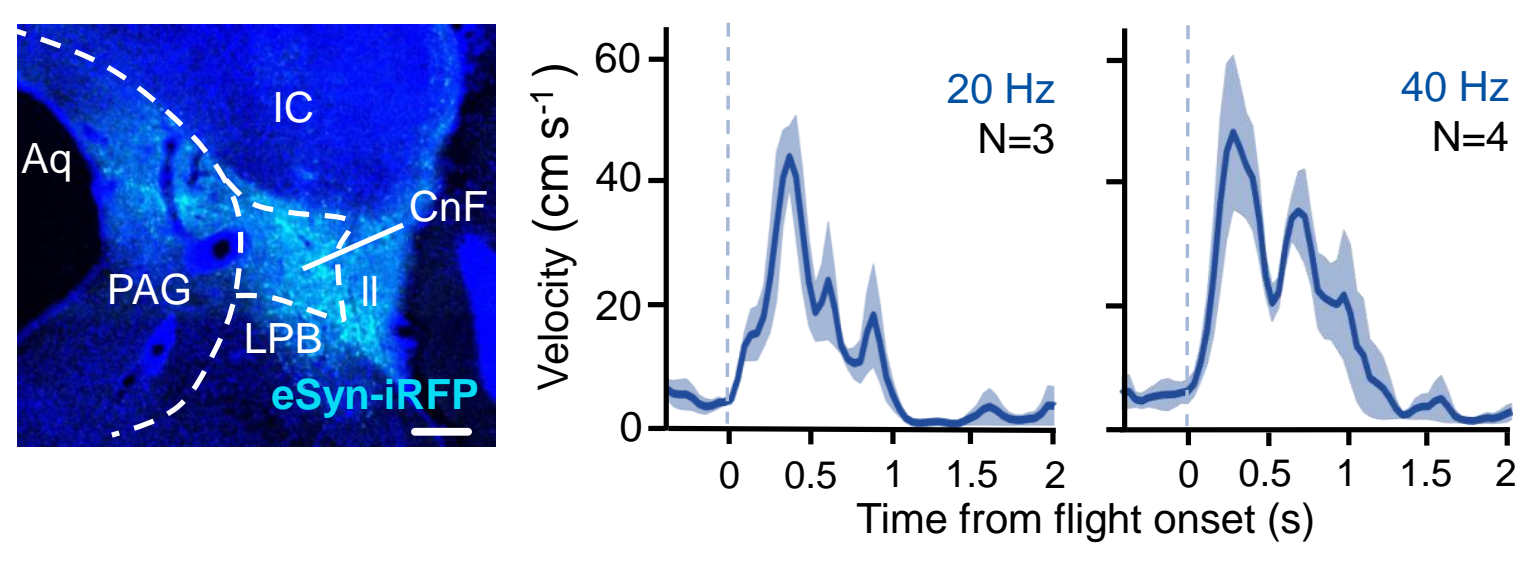

$\mathbf{F}$

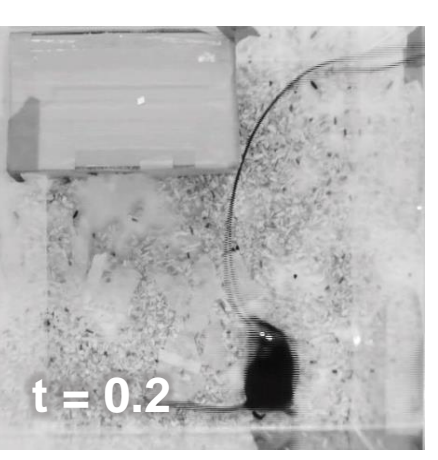

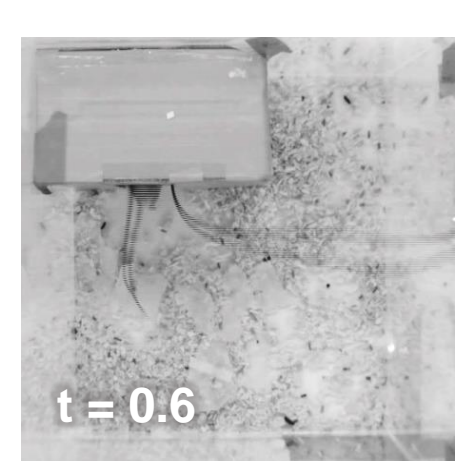


A

AAV::Ef1a-DIO-ChR2-YFP

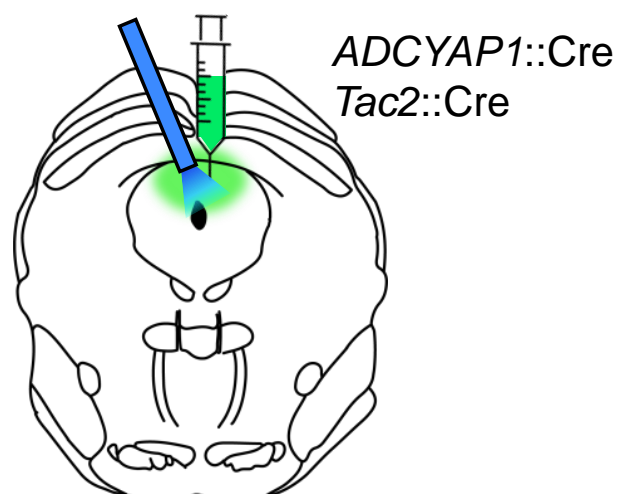

Bregma - $4.24 \mathrm{~mm}$

C

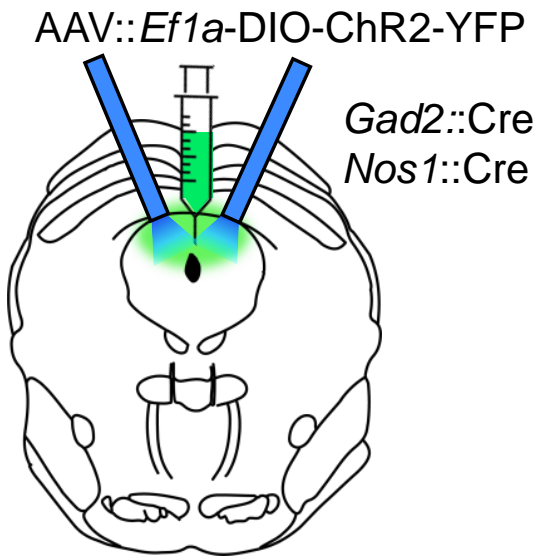

Bregma - $4.24 \mathrm{~mm}$
B
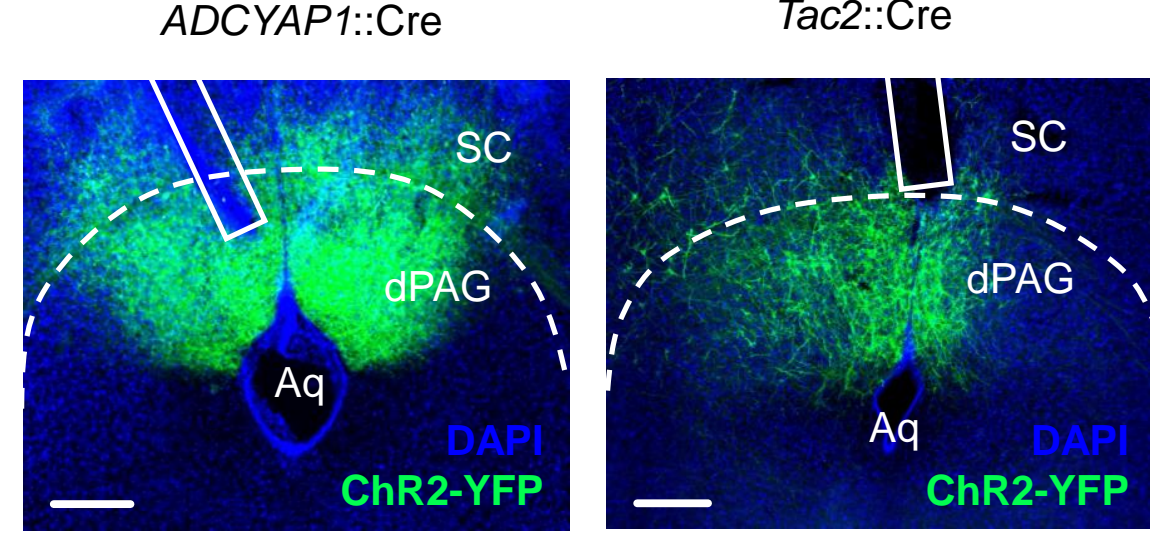

D

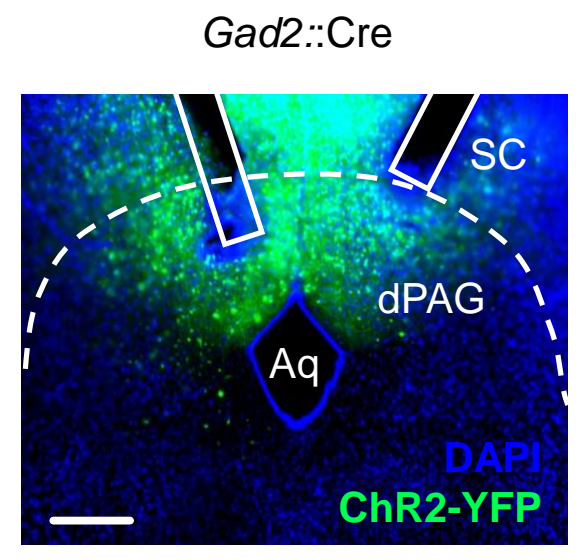

Nos 1::Cre

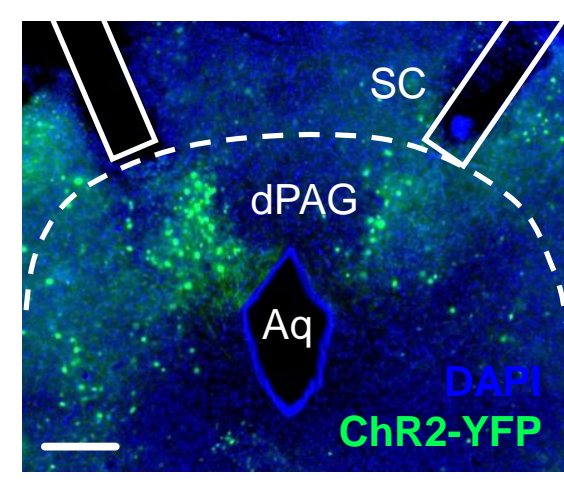

